УДК 628.334

НЕФТЯНОЕ ЗАГРЯЗНЕНИЕ ПРОИЗВОДСТВЕННЫХ СТОЧНЫХ ВОД ВАГОНОРЕМОНТНОГО ДЕПО

Д-р техн. наук В.А Юрченко, аспіранти А. В. Артеменко, О.Г. Мельникова НАФТОВЕ ЗАБРУДНЕННЯ ВИРОБНИЧИХ СТІЧНИХ ВОД ВАГОНОРЕМОНТНОГО ДЕПО

Д-р техн. наук В.О. Юрченко, аспиранты А.В. Артеменко, О.Г. Мельнікова

\title{
OIL POLLUTION OF REPAIR DEPOT INDUSTRIAL WASTE WATER
}

Doct. of techn. sciences V. Iurchenko, graduate students A. Artemenko, O. Melnikova

Установлен состав сточных вод вагоноремонтного депо в динамике локальной очистки. Проведено фракционирование нефтяного загрязнения и определено содержание наиболее экологически опасной фракиии, а также эффективности ее удаления из сточных вод при механической очистке. 
Ключевые слова: сточные воды, локальная очистка, пенополиуретановые фильтры, нефтепродукты, фракиионирование, экологическая опасность, эффективность очистки.

Установлено склад стічних вод вагоноремонтного депо в динаміці локального очищення. Проведено фракиіонування нафтового забруднення $і$ визначений вміст найбільш екологічно небезпечної фракиії, а також ефективності ї̈ видалення зі стічних вод при механічному очищенні.

Ключові слова: стічні води, локальне очищення, пінополіуретанові фільтри, нафтопродукти, фракиіонування, екологічна небезпека, ефективність очищення.

The composition of a carriage repair depot waste water in dynamics of the local purification was established in experimental researches. Processing of waste water in the sediment bowl and the petrotrap leads to effective removal of petrochemicals and suspended matters. However filters with expanded polyurethane loading work extremely unsatisfactorily. The oil pollution was fractionated. The content of the most ecologically dangerous fraction and efficiency of its removal out of waste water by the filtration through expanded polyurethane was determined.

Keywords: waste water, local purification, polyurethane filters, petrochemicals, fractionation, ecological danger, efficiency of purification.

Вступ. Производственные сточные воды на вагоноремонтных предприятиях образуются при наружной и внутренней обмывке подвижного состава, промывке и прессовке узлов и деталей, промывке и заправке аккумуляторов, при продувке оборотных систем, охлаждении компрессоров и другого оборудования, при выпуске воды из гальванических ванн, систем отопления вагонов, охлаждения дизелей и т.д. [1]. Очистка производственных сточных вод этих предприятий до экологически безопасного уровня - актуальная научная и практическая задача.

Постановка проблемы в общем виде и её связь с важными научными и практическими заданиями. Основными видами загрязнений производственных стоков для большинства предприятий железнодорожного транспорта являются взвешенные вещества минерального и органического происхождения и нефтепродукты (НП) $[1,2]$. Их содержание превышает предельно допустимые концентрации для отведения в канализационную сеть и требует предварительной локальной очистки. Для железнодорожных предприятий разработаны и внедрены как компактные устройства малой производительности, так и целые станции очистки-регенерации раствора, модульные устройства, локальные очистные комплексы.

Анализ последних исследований и публикаций. Для очистки промышленных сточных вод, образующихся на вагоноремонтных предприятиях, и сточных вод аналогичного состава применяют различные методы и технические средства: отстаивание тяжелых частиц в отстойниках, всплывание легких взвешенных частиц НП в нафтеловушках, фильтрование через фильтры с минеральной и органической загрузкой, коалесценцию мелких и эмульгированных НП в коалесцентных фильтрах, сорбцию эмульгированных НП и др. [3-5]. Эффективными устройствами для очистки сточных вод от диспергированных нефтяных загрязнений и больших взвешенных частиц являются тонкослойные отстойники, фильтры с зернистой загрузкой, скимеры, а также различные флотационные устройства [6]. НП в сточных водах представлены парафинами, циклопарафинами, асфальтенами, ароматическими и нафтеноароматическими углеводородами. Преобладание той или иной группы углеводородов придает НП различные свойства, влияющие на методы извлечения их из сточных вод или разрушения [7]. Основной особенностью этой категории стоков является их агрегативная устойчивость при невысоких концентрациях эмульгированных НП. Технология очистки эмульсионных стоков должна обеспечить полное разрушение устойчивой структуры эмульсии с последующим отделением масляной фазы от водной среды. Для разработки такой технологии необходимо идентифицировать загрязнения, определяемые интегральным показателем -НП. 


\section{Определение цели и задачи} исследований. Цель настоящего исследования - оценка фракционного состава НП, загрязняющих сточные воды вагоноремонтного депо метрополитена «Салтовское», и разработка мероприятий по их очистке до уровня нормативных требований.

\section{Основная часть исследований.} Содержание НП в водной среде определяли согласно [8]. НП из сточных вод экстрагировали хлороформом, растворитель удаляли при испарении, а остаток растворяли в гексане, отделяли полярные соединения при обработке на колонке с оксидом алюминия, удаляли растворитель и гравиметрически определяли массу остатка. При проведении анализа параллельно проводили экстракцию НП с применением только гексана. Это позволило фракционировать НП [7], загрязняющие сточные воды, разделив на фракцию условно легких углеводородов - бензин, керосин, дизельные топлива (гексановый экстракт), и фракцию условно тяжелых углеводородов высокомолекулярных и гетероорганических (разность между содержанием НП в хлороформенном и гексановом экстрактах). Более токсична и экологически опасна для природной среды условно тяжелая фракция.

На территории предприятия эксплуатируется две самостоятельных сети канализации:
- первая - для общего отведения хозяйственно-бытовых и небольших объемов производственных сточных вод без очистки в систему городской канализации;

- вторая - для сбора и отведения поверхностного стока с территории промышленной площадки на локальные очистные сооружения депо; а после очистки - в городской ливневый коллектор. Основная часть производственных сточных вод (стоки от вагономоечной машины) отводятся на локальные очистные сооружения депо отдельным трубопроводом.

Состав сточных вод, отводимых в городскую канализацию (смеси хозяйственно-бытовых и производственных) без очистки, по данным экспериментальных исследований в основном соответствует требованиям к загрязнению сточных вод, принимаемых канализационной сетью г.Харькова. Основную проблему для соблюдения ПДС при отведения сточных вод создают периодические превышения по содержанию НП, наиболее вероятно поступающих в общий сток со сточными водами от производственных операций. Это предположение подтвердили данные исследования промышленных сточных вод от отдельных производственных участков депо «Салтовское», разбавляемых при сбросе в канализацию хозяйственнофекальными сточными водами приблизительно в 350 раз (табл.1).

Таблица 1

Состав сточных вод, образующихся на отдельных производственных участках и отводимых в городскую канализацию

\begin{tabular}{|c|c|c|c|}
\hline \multirow{2}{*}{$\begin{array}{c}\text { Производственные } \\
\text { участки }\end{array}$} & \multirow{2}{*}{ 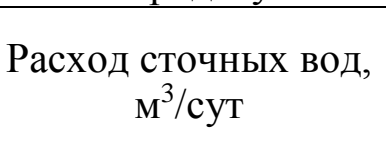 } & \multicolumn{2}{|c|}{ 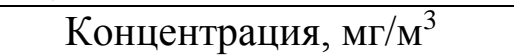 } \\
\hline & & $\begin{array}{c}\text { Взвешенные } \\
\text { вещества }\end{array}$ & НП \\
\hline Обмывка рам и тележек & 0,033 & $2340-2650$ & $4200-5690$ \\
\hline Обмывка колесных пар & 0,027 & $3690-4100$ & $3590-6120$ \\
\hline Обмывка подшипников & 0,01 & $2330-3100$ & $5132-7560$ \\
\hline Мойка лабораторной посуды & 0,6 & $115-360$ & $0,3-0,9$ \\
\hline
\end{tabular}

Таким образом, для доведения показателей состава сточных вод, сбрасываемых в городскую канализацию, до нормативных требований необходимо исключить сброс в городскую канализацию сточных вод, образующиеся на операциях обмывки рам, тележек, колесных пар и подшипников, и отвести их на локальные очистные сооружения для обработки и обезвреживания.

Сточные воды, образующиеся в производственных процессах и поступающих на локальные очистные сооружения, проходят механическую очистку, включающую отстаивание (для отделения осаждающихся взвешенных веществ и всплывающих нефтепродуктов) в нефтеловушке и фильтрацию через 
пенополиуретановую загрузку для доочистки от плохо осаждающихся взвешенных веществ и эмульгированных нефтепродуктов.
Эффективность

производственных сточных вод на различных этапах локальной очистки представлена в табл.2.

Таблица 2

Состав сточных вод вагоноремонтного депо на различных этапах механической очистки

\begin{tabular}{|c|c|c|c|c|c|}
\hline $\begin{array}{c}\text { Загрязняющие } \\
\text { вещества }\end{array}$ & $\begin{array}{c}\text { Поступающие } \\
\text { сточные воды }\end{array}$ & $\begin{array}{c}\text { После отстойника и } \\
\text { нефтеловушки }\end{array}$ & $\begin{array}{c}\text { Эффект } \\
\text { очистки, \% }\end{array}$ & $\begin{array}{c}\text { После } \\
\text { фильтров }\end{array}$ & $\begin{array}{c}\text { Эффект } \\
\text { очистки, \% }\end{array}$ \\
\hline $\begin{array}{c}\text { Взвешенные } \\
\text { вещества, мг/дм3 }\end{array}$ & $1509-3210$ & $60-130$ & $93,7-96,0$ & $38-76$ & $22,6-70,2$ \\
\hline НП, мг/дм3 & $2276-3420$ & $20-81$ & $97,6-99,1$ & $16-61$ & $10,5-67,5$ \\
\hline
\end{tabular}

Как видно, поступающие на очистку сточные воды - высококонцентрированные по содержанию НП. Однако, обработка в отстойнике и нефтеловушке приводит к эффективной очистке сточных вод от этого загрязнения, а также взвешенных веществ. Однако фильтры с ППУ работают крайне неудовлетворительно: эффективность удаления как НП, так и взвешенных веществ неустойчивая и в целом низкая.

Эффективность очистки сточных вод от НП связана с фракционным составом этих загрязнений. Данные детального исследования сточных вод, поступающих на пенополиуретановые фильтры, состав НП до и после обработки представлены в табл.3, 4.

Таблица 3

Состав сточных вод, подаваемых на фильтры локальных очистных сооружений вагоноремонтного депо «Салтовское»

\begin{tabular}{|c|c|c|c|}
\hline Показатель & Концентрация & Показатель & Концентрация \\
\hline Мутность, мг/дм ${ }^{3}$ & $53,1-130,0$ & Нитриты, мг/дм ${ }^{3}$ & $0,07-0,23$ \\
\hline $\mathrm{pH}$ & $6,5-7,6$ & Нитраты, мг/дм ${ }^{3}$ & $1,38-2,52$ \\
\hline Сухой остаток, мг/дм ${ }^{3}$ & $687-856$ & Железо, мг/дм & $0,16-0,69$ \\
\hline Щелочность, мг-экв/дм ${ }^{3}$ & $6,0-8,8$ & Хлориды, мг/дм ${ }^{3}$ & $46,1-49,0$ \\
\hline Жесткость, мг-экв/дм ${ }^{3}$ & $5.6-8,0$ & Сульфаты, мг/дм ${ }^{3}$ & $100,3-163,4$ \\
\hline Азот аммонийный, мг/дм ${ }^{3}$ & $0,23-0,60$ & НП, мг/дм ${ }^{3}$ & $17,5-94,0$ \\
\hline
\end{tabular}

Как видно, обработка на фильтрах удаляет главным образом тяжелые НП. Эффект очистки от тяжелых НП в 1,5-2 раза превосходит эффект очистки от легких НП.

А общий эффект очистки от НП коррелирует с величиной доли тяжелых НП в поступающей сточной воде (рис.).

Фракционный состав НП, удаляемых при обработке сточные вод на фильтрах вагоноремонтного депо «Салтовское»

\begin{tabular}{|c|c|c|c|c|}
\hline \multirow[b]{2}{*}{ Пробы } & \multirow[b]{2}{*}{ Сточные воды } & \multicolumn{3}{|c|}{ Концентрация, мг/дм3 } \\
\hline & & Нефтепродуктов & $\begin{array}{c}\text { Легких } \\
\text { нефтепродуктов }\end{array}$ & $\begin{array}{c}\text { Тяжелых } \\
\text { нефтепродуктов }\end{array}$ \\
\hline \multirow{3}{*}{1} & До очистки & 81,2 & 28,1 & 53,1 \\
\hline & После очистки & 19,4 & 16,7 & 2,7 \\
\hline & Эффект очистки & 76,1 & 40,6 & 94,9 \\
\hline \multirow{3}{*}{2} & До очистки & 94 & 56 & 38 \\
\hline & После очистки & 42 & 33 & 9 \\
\hline & Эффект очистки & 55,3 & 41,1 & 76,3 \\
\hline \multirow{3}{*}{3} & До очистки & 72 & 61 & 11 \\
\hline & После очистки & 61 & 44 & 11 \\
\hline & Эффект очистки & 15,3 & 27,9 & 0 \\
\hline \multirow{3}{*}{4} & До очистки & 19 & 16 & 3 \\
\hline & После очистки & 16 & 16 & 0 \\
\hline & Эффект очистки & 15,8 & 0 & 100 \\
\hline
\end{tabular}




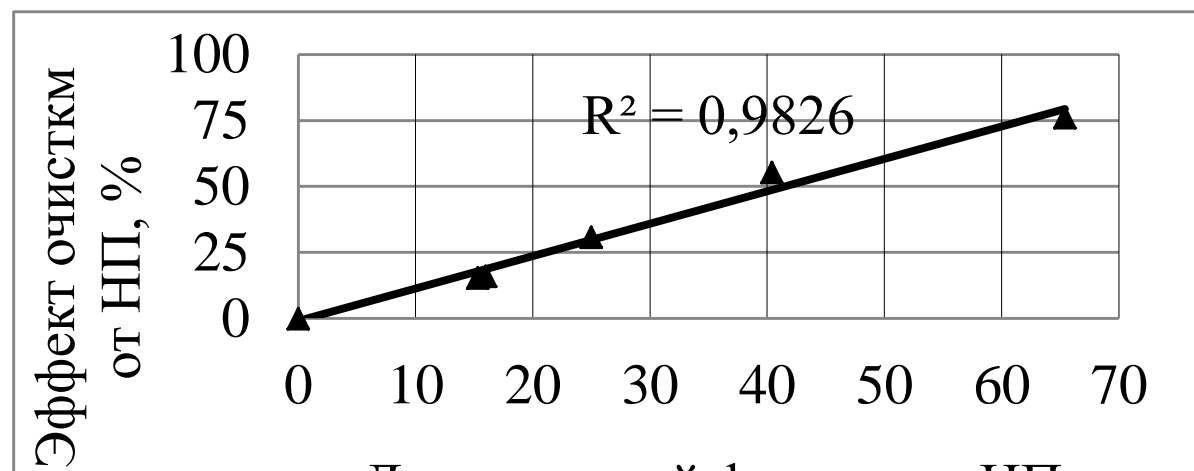

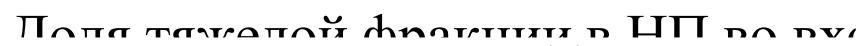

Рис. 1. Влияние доли тяжелых НП в сточной воде на эффект очистки от НП.

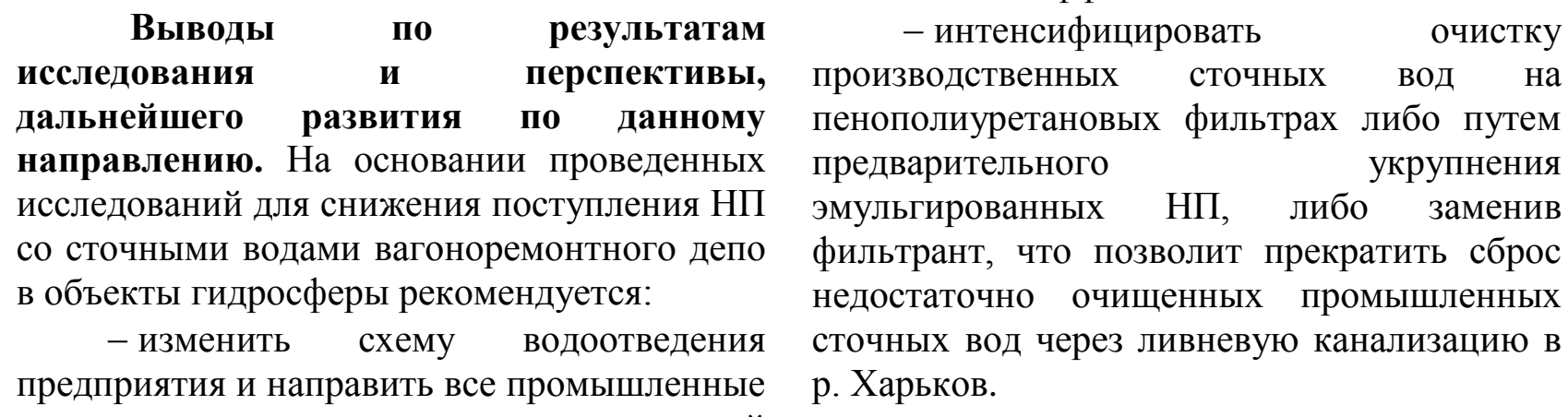
сточные воды на сооружения локальной очистки;

\section{Список использованных источников}

1. Водоснабжение и канализация на железнодорожном транвспорте. Под редакцией А.В.Теплова. -М.:Транспорт, 1973. -248 с.

2. Sheshunova N. Sewage treatment from the enterprises of a railway transportations (locomotive depot) //Научный молодёжный ежегодник. -2009. Вып. IV. C. 287-288.

3. ДБН В.2.5 - 75:2013. Каналізація. Зовнішні мережі та споруди. Основні положення проектування // К.: Міністерство регіонального розвитку, будівництва та житловокомунального господарства України, 2012. - 207 с.

4. Шаманская М.В. (Обуздина М.В.) Анализ основных технологий очистки сточных вод от нефти //Экологическая безопасность современных социально-экономических систем.Москва: Изд-во центра прикладных научных исследований. - 2009. - С. 72-77.

5. Березуцкий В.В. Доочистка и обеззараживание маслоэмульсионных сточных вод [Текст] / В.В. Березуцкий, А.Н. Древаль, Т.С. Павленко и др. // Водоснабжение и санитарная техника. - 1992. - № 3. -29 с.

6. Сапронова Ж.А. Сорбционная очистка нефтесодержащих сточных вод с помощью отходов сахарной промышленности: монография [Текст] / Ж.А. Сапронова, В.А. Юрченко, С.В. Свергузова. - Х.: ХНАДУ, 2014.- 128 с.

7. Глязнецова Ю.С. Особенности экстракции при определении нефтезагрязнений в почвах [Текст] / Ю.С.Глязнецова, И.Н.Зуева, О.Н.Чалая и др. [Электронный ресурс] // IV Международный интернет - симпозиум по сорбции и экстракции 25 апреля - 30 сентября

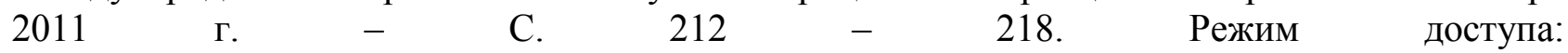
http://www.ich.dvo.ru/ isse/2011/images/stories/files/extraction.pdf.

8. Лурье Ю.Ю. Химический анализ производственных сточных вод. [Текст] / Ю.Ю. Лурье, А.И. Рыбникова.- М.: «Химия», Издание 4-е, перераб. - 1974.- 336 с.

Юрченко Валентина Александровна д-р техн. наук, профессор зав. кафедрой безопасности жизнедеятельности и инженерной экологии Харьковский национальный университет строительства и архитектуры. 
Артеменко Андрей Викторович аспирант Харьковского национального университета строительства и архитектуры.

Мельникова Оксана Григорьевна аспирант Харьковского национального автомобильно-дорожного университета. E-mail: mikh-oksana@yandex.ru

Yurchenko Valentina d-r science, professor Head. the department of life safety and environmental engineering Kharkov National University of Construction and Architecture.

Artyomenko Andrey graduate student of Kharkov National University of Construction and Architecture.

Melnikova Oksana graduate student of Kharkiv National Automobile and Highway University. E-mail: mikhoksana@yandex.ru. 